\title{
MALE-FEMALE INCOME INEQUALITY BY EMPLOYMENT STATUS IN CANADA
}

\author{
Camilo Dagum* \\ University of Ottawa
}

RESUMO

Esta pesquisa apresenta uma anālise e a aplicação de uma medida de desigualdade na distribuição de renda, levando em consideração uma diferença relativa entre unidades de populações econõmicas diferentes. Förmulas paramétricas e de livre distribuição são deduzidas; e se introduz um teste de hipótese estatistico a fim de decidir se existe ou não diferenças significantes entre as distribuições de renda de duas populações (macho e fêmea) no Canadā no período de 1969-79.

A taxa diferencial de renda $\mathrm{D}_{1}$ (usada como medida da inequalidade de renda entre distribuições) e o coeficiente de Gini dão uma sintese importante da estrutura da distribuição de renda entre macho e fêmea.

\section{ABSTRACT}

This research purports the analysis and application of a measure of income inequality between income distributions to account for the relative income differential between populations of economic units. Parametric and distribution-free formulas are deduced and a statistical test of hypothesis is introduced to decide whether or not there is a significant income differential between distributions.

(*) The Canada Department of Labour-University Research grant is gratefully ack nowledged. The author is also grateful to Leslie L. Gunarat and Mario Bedard for programming assistance. All calculations were made with the Econometric Package for Income Distribution (EPID) which is available upon request. March 1983 
This theoretical framework is applied in order to study the male-famale income differential in Canada during the 1969-1979 period. It deals with the following socio-economic attributes: (1) individuals that worked 50-52 weeks; (2) individuals that worked 1 -49 weeks; (3) individuals that did not work; (4) employees; and (5) employers.

The income differential ratio $D_{1}$ (used as a measure of the in come inequality between distributions) and the Gini ratio (used as a measure of the income inequality within a distribution) provide an important synthesis of the male-female incomedistribution struc ture. 


\section{INTRODUCTION}

The purpose of this study is two fold. One, to specify a modified version of the $D_{1}$ inequality measure between income distributions introduced by Dagum (1980.a). This new measure fully accounts for the role played by the null hypothesis as the origin of $D_{1}$ (case in which both distributions have equal means) and it also gives more reliable estimates if applied to pairs of income distri butions with highly dissimilar patterns. T'wo, this modified measure $D_{1}$ is here used to calculate tire inequality between male and fe male income distributions in Canada according to the following socio-economic categories: (i) worked 50-52 weeks, (ii) worked 1-49 weeks; (iii) did not work, (iv) employee, and (v) employer or own account.

The income differential nati- $\mathrm{D}_{1}$ (sometimes called the intenincome distribution inequality inequality between income distributions, more specifically, between populations of income units. It differs from traditionally used measures (such as those of Gini (1912) and Theil (1967)), in that the latter purport to evaluate the relative income inequality among the members of a single population. As such, they are intha-incone dis tribution inequality measures, which account for the income inequa lity within a population.

The income differential ratio $D_{1}$ also departs from the disaggre gation procedure introduced by Theil (1967) and Bhattacharya-Mahalanobis (1967), which is used for the Theil and Gini ratios respectively. Although the disaggregation approach is an important step forward to the understanding of the structure of income inequality, it has the shortcomings of: (a) starting rrom the mirture of two generaliy heterogeneous (significanily different) poplilations, and (b) providing a weighted estimate of the contribution of one of them to the inequality of the mixed pupulation, thus, it very often hides the socio-political dimension of the inequa?ity between socio-economic groups or classes. 
The measure $D_{1}$ is free of the above mentioned shortcomings. It is a measure of the relative degree of affluence of one population with respect to another, which is an asymmetric nelation. Thus, it should not be discussed as a mathematical distance function for which the symmetry property applies, as wrongly done by shorrocks $(1982)$.

This study is organized as follows: section 2 introduces a mo dified income differential ratio $\mathrm{D}_{1}$ and deduces its mathematical expression for the distribution-free form, and the parametric form corresponding to the model specified by Dagum (1977, 1980.b, 1983); section 3 deals with the statistical hypothesis testing of $D_{1} ;$ sec tion 4 discusses the male-female income differential ratio in Cana da for five types of employment, and section 5 concludes this study.

\section{THE INCOME DIFFERENTIAL RATIO D,}

Let us denote with $Q_{1}$ and $Q_{2}$ the correspondig populations of female and male individuals with income; $F_{1}($.$) and F_{2}($.$) the cumu-$ lative distribution functions $(C D F)$, and $f_{1}($.$) and f_{2}($.$) the proba$ lity density functions (PDF) of each population with respect to the income variable. The existence of a finite mathematical expectation is assumed. The subscript 1 or 2 will be attached to the ma thematical expectation operator $E$ to indicate that the weighting function is the PDF $f_{1}($.$) or f_{2}($.$) respectively. The population$ with the larger mean income is by definition the more affluent, and to this the subscript 2 is attached. Accordingly, $E_{1}(Y)<E_{2}(Y)$, therefore, $Q_{2}$ is in average more abbluent than $Q_{1}$. It defines a re lation of relative affluence and it is an asymmetric relation, for if population $Q_{2}$ is relatively more affluent than population $Q_{1}$, in symbols $Q_{2} R Q_{1}$, then $Q_{1} Q_{2}$, where the symbol $R$ stands for "is more affluent than". Moreover, if $S:($.$) is a social welfare function of$ income, then $S W\left(M_{2}\right)>S W\left(M_{1}\right)$, where $M_{i}=E_{i}(Y), i=1,2$.

As a measure of the income differential between income distri butions the following ratio is introduced:

$$
D_{1}=\left(d_{1}-a_{1}^{*}\right) /\left(\Delta_{1}-d_{1}^{*}\right)
$$


The symbols entering the right-hand side (r.h.s.) of (1) are defined below.

i) $d_{1}$ is the mathematical expectation of $Y-X$, for all $Y>X$, where $Y$ is the income variable of the more affluent population $Q_{2}$, and $\mathrm{X}$ is the income variable of the less affluent one. Hence,

$$
d_{1}=E[(Y-X) I(Y-X) \mid E(X)<E(Y)],
$$

where $I(Y-X)$ is the indicator bunction such that it assumes the value of 1 for all $Y>X$, the value $1 / 2$ for all $Y=X$, and the value zero for all $\mathrm{Y}<\mathrm{X}$. The case $\mathrm{Y}=\mathrm{X}$ is relevant when dealing with the income differential ratio $D_{0}$ and discrete distributions, where ties might be observed with non-zero probality (Dagum, 1978, 1980.a). It follows from (1) that,

$$
\begin{aligned}
d_{1} & =\int^{\infty}\left[f^{Y}(y-x) d F_{1}(x)\right] d F_{2}(y) \\
& =E_{1}\left(Y F_{2}(Y)\right)+E_{2}\left(Y F_{1}(Y)-E_{1}(Y) .\right.
\end{aligned}
$$

ii) $d_{1}^{*}$ is the value taken by $d_{1}$ when the null hypothesis

$$
\mathrm{H}_{0}: \mathrm{F}_{1}(\mathrm{y}) \equiv \mathrm{F}_{2}(\mathrm{y})
$$

applies, i.e. when the two variables are identically distributed; hence, the two distributions exhibit an equal average affluence. Under the null hypothesis (4),

$$
E_{1}\left(Y F_{2}(Y)\right)=E_{2}\left(Y F_{1}(Y)\right)=E_{1}\left(Y F_{1}(Y)\right)
$$

hence,

$$
d_{1}^{*}=2 E_{1}\left(Y F_{1}(Y)\right)-E_{1}(Y)
$$

iii) $\Delta_{1}$ is the Gini mean difference between two distributions. It is the maximum value that $d_{1}$ can take, which is the case when the two distributions do not overlap. Thus,

$$
-\Delta_{1}=E(|Y-X|)=2 d_{1}+E_{1}(Y)-E_{2}(Y) .
$$



hence,

When the mul hypothesis applies, $E_{1}(Y)=E_{2}(Y)$ and $d_{1}=d_{1}^{*}$,

$$
\Delta_{1}=2 d_{1}^{*}
$$

is the Gini mean difference (Gini, 1912) corresponding to the CDF $F_{\uparrow}(y)$.

Formulas (3), (6) and (7) have the dimension of income, hence $D_{1}$ is a dimensionless measure. It takes the value of zero when the null hypothesis (4) applies, and the maximum value of one when the two distributions do not overlap.

Replacing the symbols on the r.h.s. of (1) by their corresponding deduced formulas, we have,

$$
D_{1}=\frac{E_{1}\left({Y F_{2}}_{2}(Y)\right)+E_{2}\left(Y F_{1}(Y)\right)-2 E_{1}\left(Y F_{1}(Y)\right)}{2 E_{1}\left(Y F_{2}(Y)\right)+2 E_{2}\left(Y F_{1}(Y)\right)-2 E_{1}\left(Y F_{1}(Y)\right)-E_{2}(Y)} .
$$

$D_{1}$ can be directly estimated from the observed (distributionfree) or from a fitted (parametric) model of income distribution. In this study, the parametric estimates of $D_{1}$ are obtained from the model specified by Dagum $(1977,1980 . b, 1983)$, using Dagum et al. (1983) computer package for income distribution. Its three and four parameter versions are respectively,

(11) $F(z)=a+(1-\alpha)\left(1+\lambda z^{-\delta}\right)^{-\beta}, z>z_{0}>0, \alpha<1 ;$ $F(0)=\alpha$ and $z_{0}=0$ if $0<\alpha<1$, and $F\left(z_{0}\right)=0, z_{0}>0$ if $\alpha<0$.

For the model specification (10) and $(11), 0<\alpha<1$ and $\delta>1$, it can be shown that the formulas entering the r.h.s. of $D_{1}$ in (9) are: ${ }^{2}$

$$
E(Y)=(1-\alpha) \beta \lambda^{1 / \delta_{B}(1-1 / \delta, \beta+1 / \delta),}
$$


(13) $\quad E(Y F(Y))=\alpha E(Y)+(1-\alpha)^{2} \beta \lambda^{1 / \delta} B(1-1 / \delta, 2+1 / \delta)$, and

$$
\begin{gathered}
E_{2}\left(Y E_{1}(Y)=\alpha_{1} E_{2}(Y)+\left(1-\alpha_{1}\right)\left(1-\alpha_{2}\right) \beta_{2} \lambda_{2}{ }^{1 / \delta_{2}}\right. \\
\int_{0}^{1}(1-t)^{b} t^{-1 / \delta 2}\left[(1-t)^{a}+a t^{a}\right]^{-\beta}{ }^{1} d t
\end{gathered}
$$

where,

$$
a=\delta_{1} / \delta_{2}, b=a \beta_{1}+\beta_{2}+1 / \delta_{2}-1,
$$

and $B($.$) is the Euler beta function.$

Performing the permutation of the subscripts 1 and 2 in (14) and (15), $E_{1}\left(Y_{2}(Y)\right)$ is obtained. Formula (13) is obtained when the null hypothesis applies.

When dealing with the distribution-free approach, and the fre quencies of the observed distributions are presented by intervals of income, the symbols entering on the r.h.s. of (1) take the following mathematical forms:

$$
a_{1}=\sum_{j=1}^{k} x_{1} \sum_{y_{j}}\left(y_{j}-x_{i}\right) f_{1}\left(x_{i}\right) f_{2}\left(y_{j}\right),
$$

$$
a_{1}^{*}=\sum_{j=1}^{h} \sum_{i=1}^{j}\left(x_{j}-x_{i}\right) f_{1}\left(x_{i}\right) f_{1}\left(x_{j}\right)
$$

$$
\Delta_{1}=\sum_{j=1}^{k} \sum_{i=1}^{h}\left(y_{j}-x_{i}\right) f_{1}\left(x_{i}\right) f_{2}\left(y_{j}\right)=a_{1}+p_{1},
$$

where,

$$
p_{1}=\sum_{i=1}^{h} y_{j}<x_{i}\left(x_{i}-y_{j}\right) f_{1}\left(x_{i}\right) f_{2}\left(y_{j}\right) .
$$


It follows from the preceding formulas that the income of the population $Q_{1}$ is partitioned in $h$ intervals, where $x_{i}$ stands for the mid-income of its $i-t h$ interval $(i=1,2, \ldots \ldots, h)$, and that of $Q_{2}$ is partitioned in $k$ intervals of income, where $y_{j}$ stands for the mid-income of its $j-t h$ interval $(j=1,2, \ldots, k)$.

When the distribution-free formula of $D_{1}$ is used (i.e., when $D_{1}$ is directly obtained from the observed income distributions), the mid-income value of each interval can be estimated by one of the following procedures.

a) if the amount of income corresponding to each interval is given, the mid-income value is simply the ratio between the amount of income and the corresponding frequency of income units for each interval of income;

b) if the amount of income corresponding to each interval is not known, and model (10) or (11) was fitted, the estimated mid-income for each closed interval is itsmidpoint, and for the open-ended interval (the $h$-th interval for the population $Q_{1}$ and the $k$-th interval for the population $Q_{2}$ ) the convergence of models (10) and (11) to the pareto Law is used. It can be shown (Dagum 1980.b, p. 339) that for large values of $y$, the survival distribution function converges to

(20)

$$
S(y)=1-F(y)=\beta \lambda y^{-\lambda}
$$

for the $\operatorname{CDF}(10)$, and to

$$
S(y)=1-F(y)=(1-\alpha) \beta \lambda y^{-\delta}
$$

for the CDF (11). Hence,

$$
y_{h}=\frac{\delta}{\delta-1} y_{h-1}^{*} \quad \text { and } \quad y_{k}=\frac{\delta}{\delta-1} y_{k-1}^{*}
$$

where $\left(\mathrm{Y}_{\mathrm{h}-1}^{*}, \infty\right)$ and $\left[\mathrm{y}_{\mathrm{k}-1}^{*}, \infty\right)$ are the open-ended intervals of the observed income distributions of populations 
$Q_{1}$ and $Q_{2}$ respectively, $Y_{h}$ and $Y_{k}$ their corresponding midincome estimates, and $\delta$ the estimated parameter of the $\mathrm{fit}$ ted distribution (10) or (11), which also appears in (20) and (21);

c) finally, when the amount of income corresponding to each interval is not given and model (10) or (11) was not fitted, the mid-income of the open-ended interval is obtained from (22), where the parameter $\delta$ is obtained from the pare to model

(23)

$\log S(y)=A-\delta \log y$

fitted to the last two intervals of each distribution. The mid-income of the remaining intervals are estimated as in (b) .

3. TEST OF HYPOTHESIS OF D,

To test the goodness-of-fit of the model specified in (10) and (11), a one-sample two-sided kolmogorov-Smirnov statistic is used. Although it is one of the best tests to assess the goodness-offit of observed income distributions, since, for each level of sig nificance, it provides a maximum acceptable discrepancy between the observed and the theoretical distributions, the fact that we have to use the fitted distribution modifies the levels of significance given in the statistical tables. To provide accurate levels of sig nificance a Monte Carlo study similar to that performed by Lilliefors (1967) for the normal distribution has to be done.

The null hypothesis test $H_{0}: D_{1}=0$ is implied by the hypothe sis that the two income variables are identically distributed, and a bortiori, that the two populations considered are in average $\underline{e}$ qually affluent. Thus,

$$
\left(\mathrm{H}_{0}: \mathrm{D}_{1}=0\right) \Longleftrightarrow\left(\mathrm{H}_{0}: \mathrm{F}_{1}(\mathrm{y}) \equiv \mathrm{F}_{2}(\mathrm{y})\right)
$$

The alternative hypothesis $\mathrm{H}_{1}: \mathrm{F}\left(\mathrm{f}_{1}(\mathrm{y}) \neq \mathrm{F}_{2}(y)\right.$ includes'al ways', such as changes in means (shift), variances and asymmetries (sha- 
pe), in which the income distributions $F_{1}(y)$ and $F_{2}(y)$ can differ. For this, the one-sided two-sample Kolmogorov-Smirnov test is ade quate, where

$$
D^{+}=\sup _{\{y\}}\left[F_{1 m}(y)-F_{1 n}(y)\right]
$$

is the one-sided two-sample Kolmogorov-Smirnov (K-S) statistic, $m$ is the sample size taken from the population with lower income $\left(Q_{1}\right)$, and $\mathrm{n}$ the sample size taken from $\mathrm{Q}_{2}$.

The K-S statistic $D^{+}$can be computed from either the observed or the parametric estimates of the income distribution functions. For large samples, which is the case of observed income distributions, it can be proved (Gnedenko, 1962, p. 396) that the transfor mation $4 \mathrm{mn}\left(D^{+}\right)^{2} /(m+n)$ converge to a chisquare distribution with two degrees of freedom. Therefore,

$$
4 m n\left(D^{+}\right)^{2} /(m+n)-x^{2}(2)
$$

If the statistic obtained by application of (26) is less than the critical value $x_{\varepsilon}^{2}(2)$ for an $\varepsilon$ level of significance, the null hypothesis is accepted and the decision is that the income inequality between the two distributions under study is not significant. If not, then the two distributions are significantly different, and $D_{1}$ estimates the income differential ratio or degree of heterogeneity. Moreover, $D_{1}$ might also be interpreted as an estimator of the discriminant power, hence it is a discriminant function, since for any randomly chosen pair of economic units, the probability that the income $Y$ of the economic unit belonging to $Q_{2}$ is greater than the income $x$ of the economic unit belonging to $Q_{1}$ tends to one when $D_{1}$ tends to one. For $D_{1}=1$, the probability is also equal to one and the two distributions do not overlap. 
4. MALE-FEMALE INCOME DIFFERENTIAL IN CANADA

The income differential ratio $\mathrm{D}_{1}$ is estimated from the model (11), and when the null hypothesis $H_{0}: \alpha=0$ is accepted, model (10) is fitted to the sample of individuals with income in Canada for the odd years ${ }^{3}$ from 1969 to 1979 (Statistics Canada, 1972, 1981).

The parametric male-female income differential ratios $D_{1}$ are estimated for each year under study and for the following employment statuses:
a) individuals that worked 50-52 weeks;
b) individuals that worked 1-49 weeks;
c) individuals that did not work;
d) employees; and
e) employers or own account.

The observed distributions are grouped in 17 intervals of income. Table 1 presents the Gini ratio (G) estimated from the fitted model of income distribution specified in (6) and the sum of squared errors (SSE). The goodness-of-fit is in general very good. The estimated values of the male-female income differential ratios (IDRs) $D_{1}$, for each of the five employment statuses and the six years studied, as well as the associated estimates of the statis tic $x^{2}(2)=4 m n\left(D^{+}\right)^{2} /(m+n)$ are presented in Table 2 .

It follows from Tables 1 and 2, and Figures 1 to 5:

1) the null hypothesis $\mathrm{H}_{0}: F_{\gamma}(y) \equiv \mathrm{F}_{2}(y)$, whence, $\mathrm{H}_{0}: \mathrm{D}_{1} \equiv 0$, is clearly rejected at the 58 and even at the 0.18 significance le vels for the thirty parametric estimates of $D_{1}$. In fact, the minimum estimated chi-square is 79.0 corresponding to the $D_{1}$ ratio of male-female of employers in 1969, whereas the chi-square critical values are 5.99 and 13.82 , at the 58 and 0.18 significance levels respectively;

2) the male-female $D_{1} s$ are too high for the five employment statuses during the whole period of study. They are much higher than the 1971 estimate of $D_{1}$ between the richest (Ontario) and the poorest (Atlantic Provinces) region in Canada $\left(D_{1}=0.448\right)$, and the 
1974 U.S. White-Black family IDR estimates $\left(D_{1}=0.417\right.$ ) (Dagum, 1980.a, p. 1801);

3) the $D_{1}$ estimates for each of the five employment statuses show a dominant stationary state during the periodo 1969-1979 (Fig. 1). The estimates of the male-female IDRs of the individuals that worked between 50 and 52 weeks and those that are employees present a very mild fluctuation and signal a decreasing trend for the end of the seventies. The corresponding male-female IDR estimates for the individuals that did not work and those that are employers or work for their own account are stationary and have wide fluctua tions. The latter can be due to the business cycle and random variations. The male-female $D_{1} s$ of the individuals that worked between 1 and 49 weeks increases from 0.398 in 1969 to 0.615 in 1975 , and then decreases to 0.520 in 1979 ;

4) $D_{1}$, as a measure of the inter-income distribuiton inequality, and the Gini ratio, as a measure of the intra-income distribution inequality, provide very important insights on the structure of the male-female income distributions. They are discussed below;

5) the Gini ratios (Fig. 2) of the male and female income dis tributions of individuals that worked 50-52 weeks are the lowest and remain rather constant in time; the Gini ratios of the females are between $3 \%$ and $10 \%$ higher than those of the males;

6) Fig. 3 shows that 1977 fitted male and female income distributions ${ }^{4}$ of individuals that worked 50-52 weeks. The low asymetries are implied by the low Gini ratios of 0.288 and 0.32 for the male and female distributions respectively, whereas $D_{1}=0.768 \mathrm{re}-$ flects the dominant position of the male income distribution to the right of the female's;

7) the Gini ratios of the male and female income distributions of employees show similar patterns but are higher than the corresponding Gini ratios of the individuals that worked 50-52 weeks. On the other hand, the corresponding $D_{1} s$ have almost similar values. A low income inequality $(G)$ within the population of each sex, and a high income differential between male and female distributions are indicative of both sex discrimination and a rather rigid occu- 
pational and human capital structures. The male-female IDR $D_{1}$ takes values between 0.707 and 0.781 (Table 2 and Fig. 1);

8) Fig. 4 shows the 1977 male and female fitted income distri butions of employees. Compared with the 1977 male and female distributions of individuals working 50-52 weeks (Fig. 3), it reveals both an increase of the Gini ratio (greater asymmetry), and a similar and very high income differential ratio;

9) the male and female Gini ratios of individuals that worked 1-49 weeks and of those that did not work show a sharp increase with respect to those working between 50 and 52 weeks and the employees. They have similar ievels and patterns, and are stationary in time. The $\mathrm{D}_{1}$ estimates are very high but lower thar: those corresponding to the other three employment categories;

10) Fig. 5 presents the 1977 fitted male and female income distributions of individuals that did not work. Both high Gini ratios and the high IDR are apparent from this diagram. The former are sig nificantly higher and the latter significantly lower than the other male-female income distributions shown in Figures 3 and 4;

11) the male and female income distributions of employers present the highest $\mathrm{Gini}$ and $\mathrm{D}_{1}$ ratios (Figs. 1 and 2 ). The income $i-$ nequality within the male population of employers (Gini ratio) shows a stable stationary path, which supports the hypothesis of a stable ownership structure, and a stable firm size and activity of male employers and self employed. The male employers Gini ratios are higher than both male and female Gini ratios of all the o ther employment groups, and significantly lower than those of the female employers. The latter, besides being the highest of themall, presents an increasing path that can be due to a more dynamic approach of a minority of women to the relative better educational and work opportunities of the seventies. However, it is not showing an impact upon $\mathrm{D}_{1}$, which presents the highest IDR estimates and a sta tionary path.

\section{CONCLUSION}

The estimated values of $\mathrm{D}_{1}$ strongly indicate that the male-fe male income differentials are unacceptably high and have not de- 
clined during the analyzed period, in spite of socio-political efforts to achieve a less unequal society. However, these estinates need some qualifications that should be taken into account if intended to be used in the design of a socio-economic policy purported to reduce the male-female income differential. In fact, the contribution of the following causes to the male-female inequality must be assessed; (a) levels of schooling; (b) job experience; (c) male and female wealth distributions; and (d) sex discrimination.

NOTES

1. The income differential ratio D, has recently been applied in several studies, among others, in Barera-Flores (1982) and Gu naratne (1982).

2. The parameter subscripts in (12) and (13) were suppressed for the sake of notational simplification. It is apparent that the parameters carry the subscript 1 or 2 according to the CDF of the income variable being $F_{1}$ or $F_{2}$ respectively.

3. The odd years are chosen because, since 1971, the Survey of Consumer Finances uses the full Canadian Labour Force sample which is more than twice the size of the subsample used in the even years.

4. For space constraint, three pairs of fitted income distributions diagrams are included. They are representative of the whole set of thirty cases studied. 


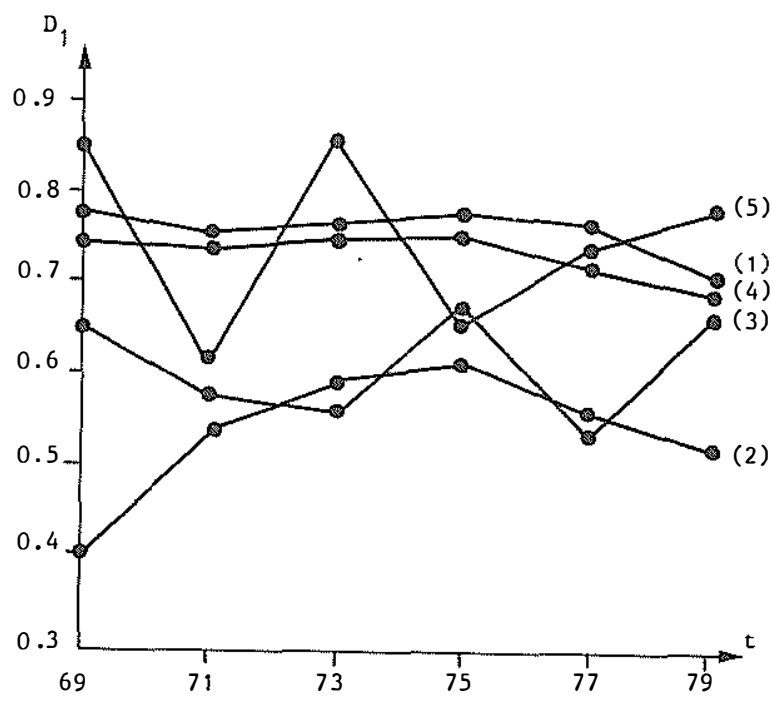

Fig. 1: Male-Female Income Differential Ratios ( $\left.D_{1}\right)$
(1) Worked 50-52 weeks
(2) Worked 1-49 weeks
(3) Did not work
(4) Employees
(5) Employers

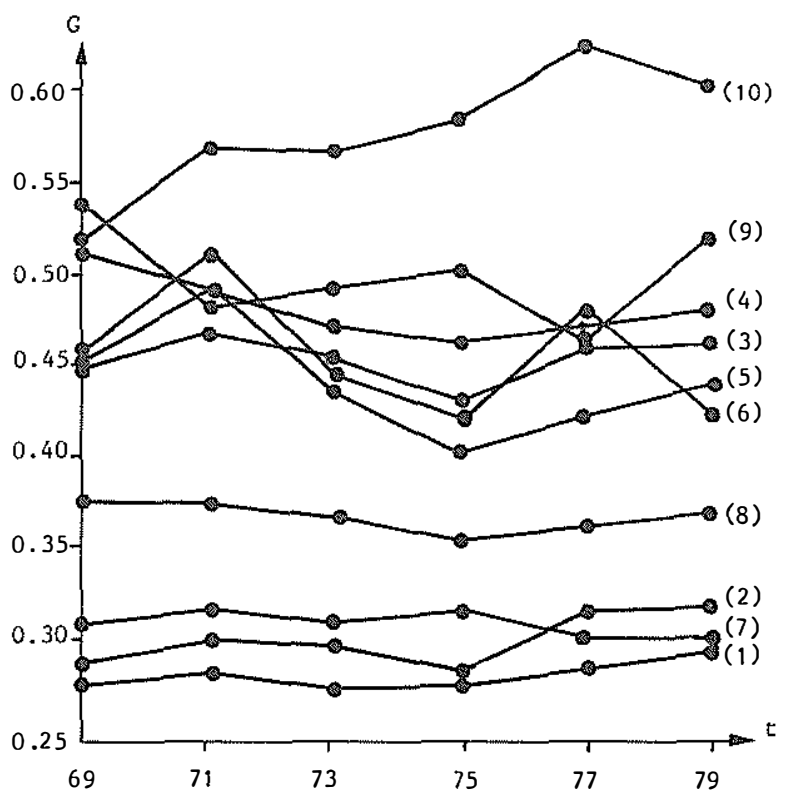

Fig. 2: Gini Ratios (G)

(i) Male, 50-52 weeks

(3) Male, 1-49 weeks

(5) Male, did not work

(7) Male, employee

(9) Male, employer 


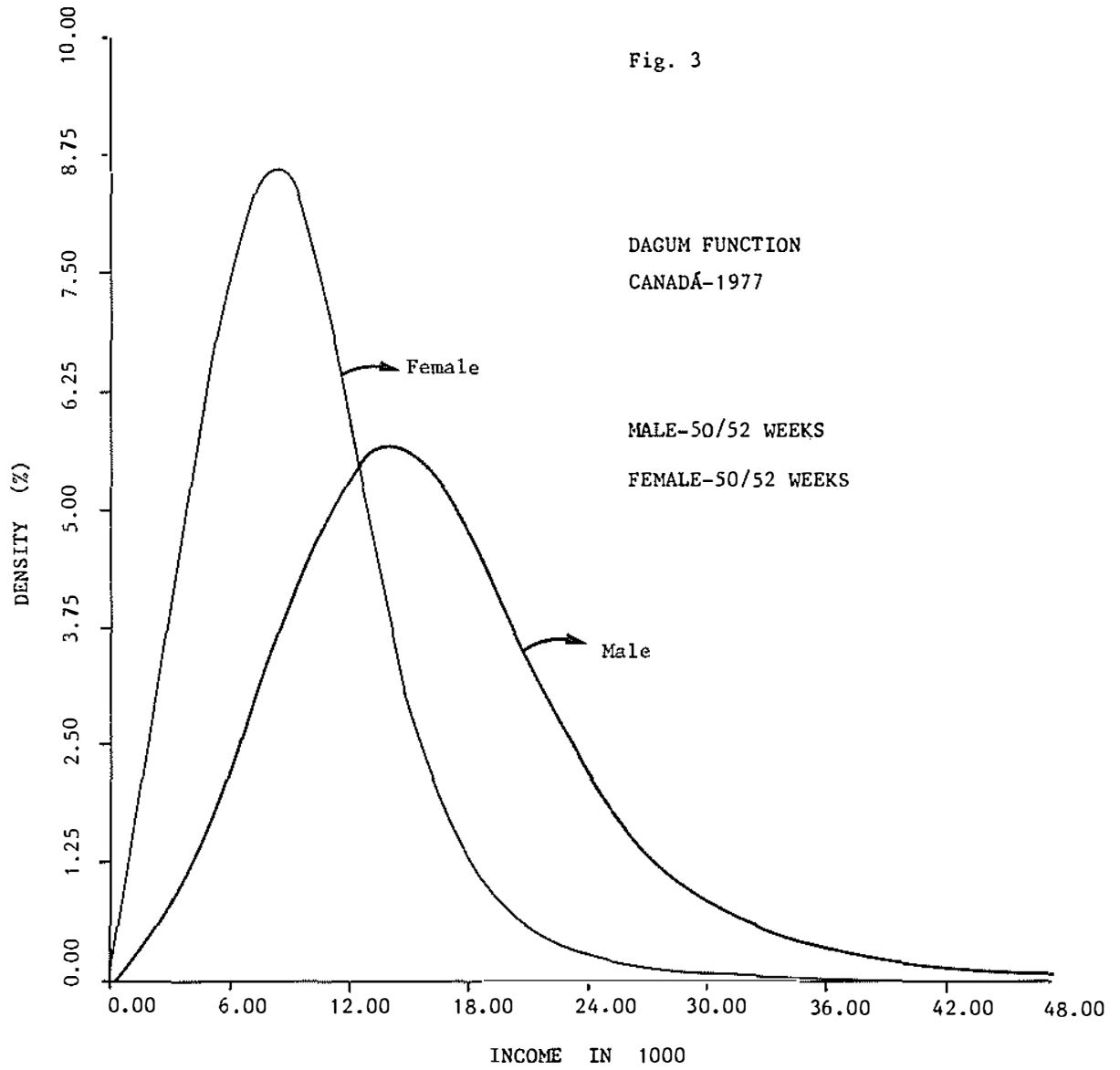

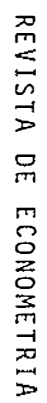




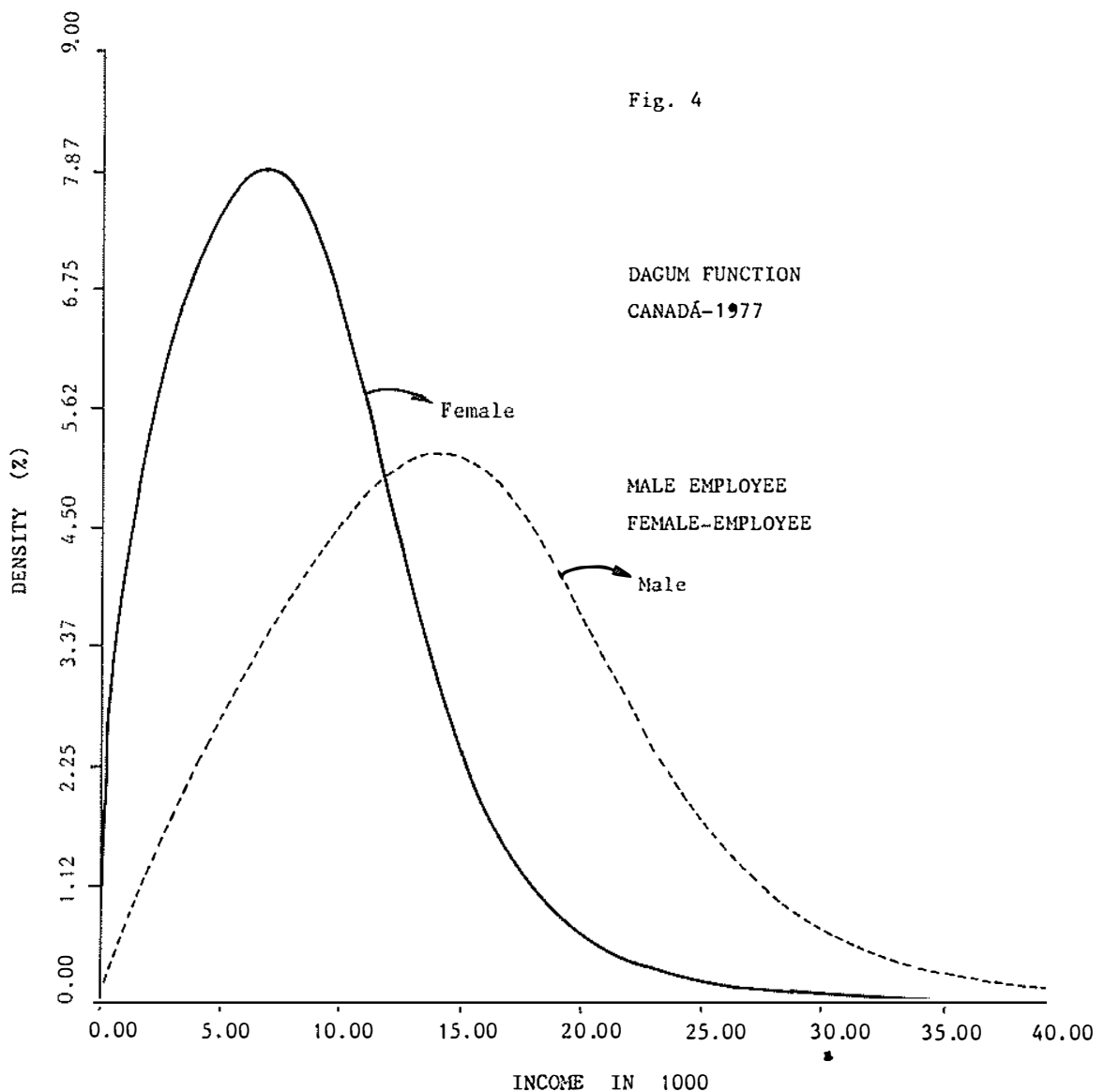

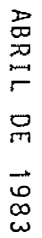

DAGUM FUNCTION

CANADÁ-1977

ALE EMPLOYEE

MALE EMPLOYE 


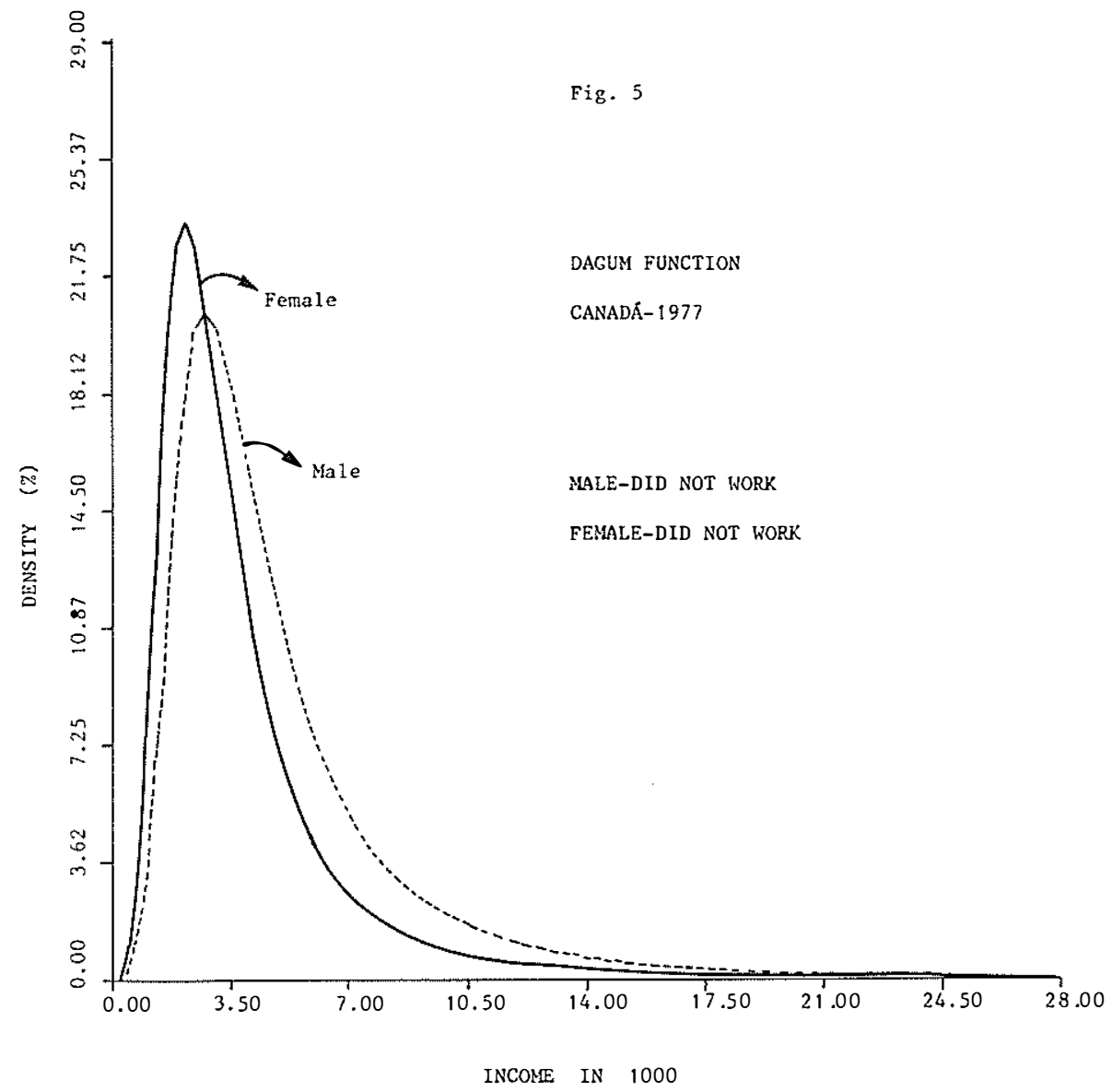




\section{REFERENCES}

J.G. Barrera-Flores (1982): Income Distribution and Redistribution: A Case Study of Mexicu. Ph.D. Thesis, The University of Ottawa, Ottawa, Canada.

N. Bhattacharya and B. Mahalanobis (1967): "Regional Disparities in Household Consumption in India". Jounnal of the American Statis tical Association, 62, 317, pp. 143-161.

C. Dagum (1977): "A New Model of Personal Income Distribution: Spe cification and Estimation", Economie Appliquēe, xxx(3), pp. 413 436 .

C. Dagum (1978): "A Measure of Inequality Between Income Distributions". Economie Appliquée, XXXI(3-4), pp. 401-413.

C. Dagum (1980.a): "Inequality Measures Between Income Distributions With Applications". Econometrica, 48(7), pp. 1791-1803.

C. Dagum (1980.b): "The Generation and distribution of Income, the Lorenz Curve and the Gini Ratio", Economie Appliquēe, XXXIII(2), pp. 327-367.

C. Dagum (1983): "Income Distribution Models". Foithcoming in Ency clopedia of Statistical Sciences. N.L. Johnson and S. Kotz (eds.), Vol. IV. New-York: John Wiley and Sons.

C. Dagum, Kim Chiu, L.L. Gunaratne and B. Barletti (1983): Econometric Package for Income Distribution (EPID). Ottawa: University of Ottawa and Time Series Research and Analysis Division, Statistics Canada.

C. Gini (1912): "Variabilità e Mutabilità". Studi Economico-giuridici, Università di Cagliari, III, 2a In C. Gini (1955), pp. $211-382$.

C. Gini (1955): Memorie di Metodologia Statistica. V०l I: Variabilită C Concentrazione. Edizioni aggiornata a cura di E. Pizet$\mathrm{ti}$ e T. Salvemini. Roma: Libreria Eredi Virgilio Veschi.

B.V. Gnedenko (1962): The Theory of Probability. New-York: Chelsea Publishing.

L.L. Gunaratne (1982): Human Capital and Distribution of Personal In come: A Theoretical Analysis and an Examination of Some Aspects of Income Distribution

sity of Ottawa, Ottawa, Canada.

H.W. Lill iefors (1967): "On the Kolmogorov-Smirnov Test for Normality ith Mean and Variance Unknown". Journal of the American Sta tistical Assciation, 62, 317, pp. 399-402. 
A.F. Shorrocks (1982): "On the Distance Between Income Distributions". Econometrica, 50(5), pp. 1337-1339.

H. Theil (1967): Economics and Information Theory. Amsterdam: NorthHolland Publishing Company.

Statistics Canada (1972): "Income Distribution by Size in Canada in 1969". Catalogue 13-544.

Statistics Canada (1981); "Income Distribution by Size in Canada". Catalogue 13-207, Bilingual annual publication since 1971. 